\title{
Applying Game Theory and Real Options to Competitiveness in Construction Businesses
}

\author{
Martha Garcia-Saenz \\ Purdue University North Central
}

\section{Introduction}

Net Present Value (NPV) has been the tool used to decide about the future of many projects for a long time. Refinements in calculations are necessary on a daily basis because of global business competition. Better tools for decision-making are indispensable for managerial flexibility in order to respond quickly to changes. For many years, decision-making was tied to strategies fixed in advance, and when projects finished on time managers were considered good ones. Nowadays, management has to be more active; managers have to look constantly for alternatives in order to know what actions to take when information arrives.

Recently in a global market, managerial flexibility has been linked to financial options, more specifically to Real Options. This brings the strategies of the financial market into real projects and helps managers make better decisions. When two or more builders or developers are ready to start similar projects in the same area for example, a strategic investment has to be analyzed under a competitive environment. If one of the builders does the first move, competitive reactions will follow when the second competitor decides to also build. Two theories: a Real Options Valuation, imported from the stock market, and Game Theory, imported from the industrial organization, can analyze and explain the competitive reaction to the strategic investment and give the owner of the project the flexibility to find the optimal time to build, often ignored by the Net Present Value analysis. NPV accepts or rejects a project without the ability to determine the optimal time to invest when a competitor affects the investment opportunity. Through simple cases, this paper shows the advantages and disadvantages in decision making when NPV value is applied, and when the Real Option valuation and game theory are used to help understand a competitive environment.

\section{Net Present Value (NPV) and Discount Cash Flow (DCF)}

For a long period of time, the future of a project has been decided using Net Present Value (NPV) and Discounted Cash Flow. NPV is defined as the present value of all future cash returns, discounted at the appropriate interest rate given by the market, minus the value of the investment. The basic logic of discounted cash flow valuation methodologies is built upon the simple relationship between present value and future value. The concept is:

"Proceedings of the 2004 American Society for Engineering

Education Annual Conference \& Exposition

Copyright (C) 2004, American Society for Engineering Education” 


$$
\text { Net Present Value }=\frac{\text { Future Value }}{1+\text { Interest Rate }}-\text { Investment }
$$

When the valuation involves more than a year, the following equation is used:

Net Present Value $=\sum_{T=0}^{n} \frac{E(C F)_{T}}{(1+r)^{T}}-I$

Where $E(C F)_{T}$ are the expected future cash flows, discounted at the market risk rate $r . T$ is the number of years and $I$ is the initial investment or cost of the project.

This method is simple, but has to be carefully used. Risky cash flows have to be discounted at a risk-rate, and inflation must be handled consistently. The rule to measure the future of a project is simple too: "An investment is worth if it has a positive NPV, and if the investment has a negative NPV, it should be rejected." 1 These rules have many times killed projects before they are even born.

In order to understand better this topic, lets say BDS Corporation is planning to buy land for $\$ 120,000$ to develop a condominium. The intention of the company is to build seven (7) apartments type A or 11 apartments type B. Current value of apartment A is $\$ 97,000$ and type B is 105,000 and the cost are 80,000 and 95,000 respectively. Could the company build the project this year?

Because the project will be build this year, time $\mathrm{T}=0$. Table No. 1 shows the NPV calculations for both alternatives. Cash Flow $(\mathrm{CF})$ will be in this case equal to $n^{*}(P-X)$ where $n$ is the number of units to build, $P$ is the actual value of each unit and $X$ is the unit cost of each unit. En reason that both NPVs values are negative there is no way BDS Corporation decides to build it.

\begin{tabular}{|l|c|c|}
\hline Alternative & $\mathrm{A}$ & $\mathrm{B}$ \\
\hline & \multicolumn{2}{|c|}{ Discount Cash Flow } \\
\hline $\mathbf{I}=$ Land Cost & $\$ 120,000.00$ & $\$ 120,000.00$ \\
\hline $\mathbf{n}=$ number of units & 7 & 11 \\
\hline $\mathbf{P}=$ Actual selling pricea & $\$ 97,000.00$ & $\$ 105,000.00$ \\
\hline $\mathbf{X}=$ Unit Cost & $\$ 80,000.00$ & $\$ 95,000.00$ \\
\hline $\mathbf{T}=$ time & 0 & 0 \\
\hline NPV & $(\$ 1,000.00)$ & $(\$ 10,000.00)$ \\
\hline
\end{tabular}

Table No. 1 Net Present Value for alternatives A and B

NPV analysis does not allow considering future uncertainty and analyzing strategic response to future events. To get the NPV of a project all strategies are fixed in advance and the value of the option to wait to see how the market unfolds to take the decision to build cannot be value. Buy the land today for example, and build next year can be analyzed as is shown in table 2 under the assumptions that the selling price increases $\$ 2,000$ dollars for each apartment type and that the cost of each apartment stays fixed. The market rate used is $17 \%$, which reflects the risk of the

"Proceedings of the 2004 American Society for Engineering

Education Annual Conference \& Exposition

Copyright (C) 2004, American Society for Engineering Education”" 
market. Results show again that the NPV is negative for both alternatives, and then according with the rule, this project cannot be build. No body wants to loose money.

Suppose you can buy the land, build 3 units this year and wait to see what happens in a year to analyze the behavior of the market and decide to build or not to build. Managers can develop some scenarios and get results from them but they cannot quantify the option to take decisions later when information arrives.

\begin{tabular}{|l|c|c|}
\hline Alternative & $\mathrm{A}$ & $\mathrm{B}$ \\
\hline & \multicolumn{2}{|c|}{ Discount Cash Flow } \\
\hline $\mathbf{I}=$ Land Cost & $\$ 120,000.00$ & $\$ 120,000.00$ \\
\hline $\mathbf{n}=$ number of units & 7 & 11 \\
\hline $\mathbf{P}=$ Actual selling price & $\$ 99,000.00$ & $\$ 107,000.00$ \\
\hline $\mathbf{X}=$ Unit Cost & $\$ 80,000.00$ & $\$ 95,000.00$ \\
\hline $\mathbf{T}=$ time & 1 & 1 \\
\hline $\mathbf{r}=$ Market Rate & 0.17 & 0.17 \\
\hline NPV & $(\$ 6,324.79)$ & $(\$ 7,179.49)$ \\
\hline
\end{tabular}

Table No. 2 Alternative values when project is build one year from now

In the 1970's, Net Present Value (NPV) and Discounted Cash Flow (DCF) were the best practices for valuing corporate assets. NPV and DCF analysis fail to consider future uncertainty and strategic response to future events. In principle, DCF analysis can be dynamic and can incorporate uncertainty. With dynamic discount cash flow analysis, the most difficult inputs to estimate are the probabilities of future cash flows and the proper risk-adjusted discount rates. NPV and DCF do not take into account the managerial flexibility that allows mangers to take better decisions when new information arrives. It takes implicit assumptions related with the scenarios of cash flows and expects a passive management to get the results founded today with the information available.

\section{Weighted Average Cost Of Capital (WACC)}

Market discount rate intends to cover the risk of the market, but risk is inherent to each company or each investor. Because of it, practitioners started discounted the cash flows with the Weighted Average Cost of Capital (WACC). It was the first step towards incorporating uncertainty. The WACC approach begins with the insight that the firms are financed with both debt (B) and equity (S). The cost of capital is a weighted average of the cost of debt $(B)$ and the cost of equity $(S)$. Then the formula for the NPV given in equation 2 can be re-written as:

$$
\text { Present Value }=\sum_{T=0}^{n} \frac{E(C F)_{T}}{\left(1+r_{W A C C}\right)^{T}}
$$

Where:

$$
r_{W A C C}=\frac{S}{S+B} r_{S}+\frac{B}{S+B} r_{B}\left(1-T_{C}\right)
$$

"Proceedings of the 2004 American Society for Engineering Education Annual Conference \& Exposition 
$r_{\mathrm{B}}$ is the cost of the debt, $r_{\mathrm{S}}$ is the cost of the equity, and $\mathrm{T}_{\mathrm{C}}$ is the corporate tax rate.

When $r_{\text {WACC }}$ is used as a discount rate, it is supposed to pick up the tax advantage associated with corporate borrowing. Nevertheless, these approaches ignore or cannot properly capture management's flexibility to adapt and revise later decisions. Previous approaches, in particular, make implicit assumptions and expect management's commitment to a certain operating strategy to get the calculated results.

Returning to our example, the BDS Corporation believes that borrowing money, they can take advantage of the interest tax deductible at the corporate level. The company can borrow $\$ 40,000$ (B) dollars from the bank at a rate $r_{B}=0.17$ and invest its own money to complete the $\$ 120,000$ dollars to buy the land today. Company expects a return of $r_{S}$ equal to $15 \%$ over its equity. Additionally BDS Corporation has a tax structure of $30 \%$. As in the previous example, managers of the company expect for the next year that cost of the apartments will be $\$ 80,000$ and $\$ 95,000$ and the price of the apartments will be $\$ 99,000$ and $\$ 107,000$ dollars for types A and B respectively. BDS Corporation would like to know if taking in account the risk structure of the company instead of the market risk, the project could be viable. Doing the calculations (shown on Table No. 3), we found again that the NPVs are negative and according with the rule, this project cannot be build.

\begin{tabular}{|l|l|l|}
\hline Alternative & A & B \\
\hline & Discount Cash Flow \\
\hline I = Land Cost & $\$ 120,000.00$ & $\$ 120,000.00$ \\
\hline $\mathbf{n}=$ number of units & 7 & 11 \\
\hline $\mathbf{P}=$ Actual value & $\$ 99,000.00$ & $\$ 107,000.00$ \\
\hline $\mathbf{X}=$ Unit Cost & $\$ 80,000.00$ & $\$ 95,000.00$ \\
\hline $\mathbf{T}=$ time & 1 & 1 \\
\hline $\mathbf{r}=$ Market Rate & 0.17 & 0.17 \\
\hline $\mathbf{r B}=$ Cost of debt & 0.12 & 0.12 \\
\hline rS=Cost of equity & 0.15 & 0.15 \\
\hline Tc $=$ Corporate Taxes & 0.3 & 0.3 \\
\hline rwacc= & 0.13 & 0.13 \\
\hline $\mathbf{S}=$ equity & $\$ 80,000.00$ & $\$ 80,000.00$ \\
\hline B $=$ Debt & $\$ 40,000.00$ & $\$ 40,000.00$ \\
\hline NPV & $\$ 2,092.20)$ & $(\$ 2,978.72)$ \\
\hline
\end{tabular}

Table No. 3 NPV calculations taking in account the risk structure of the company

Until this point all samples and calculation suppose there is no body around building the same type of project. The builder is the only providing this type of apartments or in other words, there is not competitor around in that area.

Competitive interactions and uncertainties modify cash flows and usually make them differ from what managers expect. As new information arrives and uncertainty about future cash flows is

"Proceedings of the 2004 American Society for Engineering Education Annual Conference \& Exposition Copyright (C) 2004, American Society for Engineering Education”" 
gradually resolved, managers may find that allowing projects to vary from the originally anticipated strategy can made them more valuable. For example, managers may be able to defer, expand, contract, abandon, or alter a project at various stages during its useful life. By assuming only one cash flow scenario from the beginning, the described methodologies do not allow the value creation of flexibility.

Sometimes, firms invest to enter a new market with a project with negative NPV because it positions the firm advantageously in the market and creates options for valuable future opportunities. This is an example of a multistage decision that potentially involves options to expand, abandon or alter the project at a future date. When firms did it in the past was because they visualized new future opportunities. These opportunities to invest in projects with multi stages are analogous to a call option, as it will be explained latter in this paper.

\section{Decision Tree Analysis (DTA)}

A Decision Tree Analysis is an improvement in calculations when valuing flexibility. The basic structure of the decision tree is as follows: management is faced with the decision of choosing among alternative actions; the consequence of each alternative action depends on some certain future event which management can measure probabilistically on the basis of past information, or additional future information obtainable at some cost. This means, managers should choose the alternative that maximize the value of the project. But decision tree analysis is a straightforward way to plan future decisions and sources of uncertainty that relies on subjective assessments of probabilities. Example will not be presented in this section, because the following section of Real Options will use the decision tree analysis format.

The decision rule in DTA is simple: choose the one that offers the best average value of the outcomes by their probabilities of occurrence ${ }^{2}$. However, DTA uses a NPV as an input and it of course, shares some of the NPV's disadvantages. The problem of the discount rate is still present in this method and of course the risk associated with it.

Traditional tools work well when there are options with very little uncertainty, but when more complex problems exist and uncertainties are present, better tools are necessary. Here is when Real Options can help.

\section{Real Options Approach (ROA)}

When the owner of a project delays an investment until the results of a pilot program are known, it is because he or she is intuitively using options. The decision about when to complete the project or not invest in the program is a contingent investment decision that depends on an uncertain outcome. Valuing investment opportunities that contain future contingent decisions is hard, but can be done with the Real Options Approach (ROA) valuation. The concept behind ROA may be what was intuitive for some managers before, but since the second part of the decade of the 1990s, and especially after Scholes and Merton received a Nobel Prize in Economics (Dec-1997), some scholars and consultant firms in the financial sector have found that many decisions can be analyzed using options as a framework. ROA is based in the theory used at the stock market to value futures and it was developed by Black, and Scholes ${ }^{3}$ at the

"Proceedings of the 2004 American Society for Engineering

Education Annual Conference \& Exposition

Copyright (C) 2004, American Society for Engineering Education”" 
beginning of the seventies and since then, it is used extensively at the stock market. But was only after the Nobel Prize in December of 1997 announced the possibility of using this theory in real projects when, it get the enough attention from the financial community. Options are unfamiliar for engineers and many of them can see the real option approach as a mysterious. That is why is important to teach them and modify the corporate culture to incorporate options as a new way of thinking of design and manage strategic investments on projects actively.

Options are contingent of decisions, an opportunity to make a decision after seeing how events unfold. On the decision date, if the events have turned out well, we can make one decision, but if they have turned out poorly, we can make another decision. This means the payoff is not linear. Payoff refers to the cash or result of a particular series of actions realized by the holder of an option at the end of its life. A fixed decision has linear payoffs because no matter what happens, we will make the same decision. We can use Real Options when there is a contingent investment decision, when it is important to wait for more information, when uncertainty is an ingredient for earning flexibility, and when project updates can introduce strategy corrections in the project.

Incorporating flexibility and strategic investments during the development of a project, radically changes the management of a project. Changes are necessary; we have to move to a more active management. In advance, the project manager should look for alternatives and options involved in the project, and in advance, he or she should know what actions to take when information arrives.

A Call Option (C) is the right to do something for a specific price (E), on or before a specific date. If the option is exercised before maturity, it is called an American option; if it is exercised at maturity, a European option. A call option gives the owner of the option the right, but not the obligation to do something (for example buy or build). The owner of the option uses the option only if it is a smart thing to do; otherwise, the option can be thrown away. In an option notation $\mathrm{C}$ is the value of the option.

$$
C=\left\{\begin{array}{cc}
0 & \text { if } S_{T} \leq E \\
S_{T}-E & \text { if } S_{T}>E
\end{array}\right.
$$

Where $E$ is the exercise price: It is the fixed price at which the holder (the owner) can buy or sell the underlying asset. Selling price is the case for BDS Corporation. $T$ is the expiration date: It is the date the option expires. After this date, the option is dead. $S$ is the value of the underlying assets: This is an asset with the same risks as the assets that the firm would own if the investment were made.

BDS Corporation knows that uncertainties about the future price of the apartments create value that cannot be measure with traditional tools. Additionally, company knows that Real Options approach can quantify the option to delay the project, and give some insights to help in the decision to build apartments type A or type B.

Returning to the same sample we analyzed before, BDS Corporation plan to buy a land today at a cost of $\$ 120,000$. They can see the value of the land as an option to develop now or wait for

"Proceedings of the 2004 American Society for Engineering

Education Annual Conference \& Exposition

Copyright (C) 2004, American Society for Engineering Education” 
another year. If the company waits one year to see how the market turns, there is equal probability for the markets to fall or to grow. Next year, the value of each apartment type A (period 1) could be either $\$ 116,400(\mathrm{Pu})$ if the market grows or $\$ 80,833(\mathrm{Pd})$ if market falls down and $\$ 126,000$ if the market grows or $\$ 87,500$ if market falls down for apartments type B. It means could go up $u=1.2$ or down $d=1 / u=0.83$. Actual risk free of return is $r_{f}=4 \%$. See table 4 for calculations.

With 11 units, the $C$ value at period 1 will be $\$ 341,000$ if the market turns favorable or $\$ 0$ if the market turns down as shown on the last two columns of Table 4 . In option valuation, if $X-E$ is a negative value, the option valuation becomes zero. With 7 units the upper and low value are $\$ 254,800$ and $\$ 5,833$ as shown on the first two columns of Table 4. Since there is an option to develop the land next year instead of now, and given that BDS Corporation can decide about the building size, they can wait until next year and see: if the market turns favorable they can develop the building with eleven apartments; if the condition of the market turns down, they will develop the small building with seven apartments.

\begin{tabular}{|l|c|c|c|c|}
\hline & $\mathrm{A}$ & $\mathrm{A}$ & $\mathrm{B}$ & $\mathrm{B}$ \\
\hline & \multicolumn{4}{|c|}{ Option Valuation } \\
\hline $\begin{array}{l}\text { Land } \\
\text { Cost }\end{array}$ & $\$ 120,000.00$ & $\$ 120,000.00$ & $\$ 120,000.00$ & $\$ 120,000.00$ \\
\hline $\mathbf{n}$ & 7 & 7 & 11 & 11 \\
\hline $\mathbf{P}$ & $\$ 116,400.00$ & $\$ 80,833.33$ & $\$ 126,000.00$ & $\$ 87,500.00$ \\
\hline $\mathbf{X}$ & $\$ 80,000.00$ & $\$ 80,000.00$ & $\$ 95,000.00$ & $\$ 95,000.00$ \\
\hline $\mathbf{T}$ & 1 & 1 & 1 & 1 \\
\hline $\mathbf{r}$ free & 0.05 & 0.05 & 0.05 & 0.05 \\
\hline $\mathbf{C}$ & $\$ 254,800.00$ & $\$ 5,833.33$ & $\$ 341,000.00$ & $\$ 0$ \\
\hline $\mathbf{C}$ & $\mathrm{C}_{\mathrm{A}}{ }^{\mathrm{u}}$ & $\mathrm{C}_{\mathrm{A}}{ }^{\mathrm{d}}$ & $\mathrm{C}_{\mathrm{B}}{ }^{\mathrm{u}}$ & $\mathrm{C}_{\mathrm{B}}{ }^{\mathrm{d}}$ \\
\hline
\end{tabular}

Table No. 4 Option valuation delaying the construction 1 year

Now we can look at the problem with the bimodal model, and using the risk free rate, we can continue structuring the solution. As Real Options do, now we have to solve the tree going backwards in time as depicted in Figure 1.

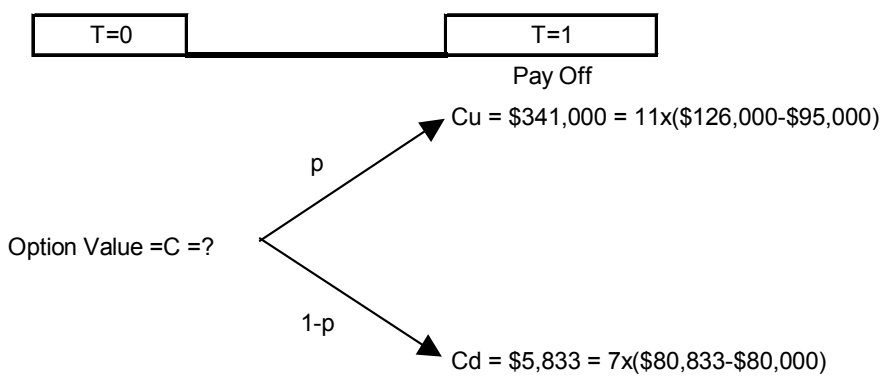

Figure No. 1 Option Valuation

"Proceedings of the 2004 American Society for Engineering Education Annual Conference \& Exposition Copyright (C) 2004, American Society for Engineering Education" 
Knowing there is a project today with the payoff shown in Figure 1, we have to calculate the probability of having a project with those payoffs today. The probabilities under the risk-neutral valuation are:

$\begin{array}{llll}\mathrm{p}= & & 0.47 & \text { If market moves up } \\ 1-\mathrm{p}= & = & 0.53 & \text { If market moves down }\end{array}$

The value of the land with the embedded option will be:

$\mathrm{C}=\quad \frac{\mathrm{p}^{*} \mathrm{C}_{\mathrm{u}}+(1-\mathrm{p})^{*} \mathrm{C}_{\mathrm{d}}}{1+\mathrm{r}_{\mathrm{f}}}=\$ 154,086.63$

Given that the land has a cost of $\$ 120,000$ the difference or $\$ 34,086$ corresponds to the value of the option. Deferring the project one year made it valuable.

One of the obstacles that could be found in this type of problems could be to establish the ups and downs of the market. In conclusion, buying the land now and developing the project immediately, implies loosing money, but buying the land now and waiting one year to see how the markets turns, is worthy. If the market does well BDS Corporation can build 11 apartments one year from now and have a profit. If market does poorly, they can build 7 apartments. Waiting in this case has always value. This model can be extended in a time horizon, holding the land, paying the expenses until the perfect time to build is found. When time runs out there is not an option to delay the project.

A decision tree that is driven by more than two sources of uncertainty is very difficult to analyze. To quantify the uncertainties, we can use management estimates, which are usually challenging because traditional methods do not require estimates of project volatility, only the expected free cash flows, and a discount rate based on systematic risk. "When Real Options are involved, simulations may be a powerful tool for determining the relevant certainty-equivalent" 4 . Samuelson $^{5}$ demonstrated that simulations could provide information about project volatility using NPV methods that are necessary for the real options solution method.

The problem we studied has uncertainties about selling price, quantity of output and cost per unit. We can use Monte Carlo simulation analysis ${ }^{6}$ to produce an estimate of project NPV values that take into account the uncertainties of major project variables ${ }^{7}$. Selling price, construction cost, and number of units to build each year are random variables following particular distributions. A simulation of the project duration is then replicated to produce a normal distribution of expected NPV values or the expected Cash flows when a decision tree analysis is used in the project valuation. This distribution of returns provides the standard deviation needed at the formula (7) that defines the ups value of the assets through time. The downs as are shown in (8) are related with the ups and of course to the standard deviation.

$u=e^{\sigma \sqrt{\frac{T}{n}}}$

"Proceedings of the 2004 American Society for Engineering Education Annual Conference \& Exposition Copyright (C) 2004, American Society for Engineering Education” 
$d=\frac{1}{u}$

$T$ is number of years, $n$ the number of periods. In our previous example we supposed $\mathrm{u}=1.20$ and as a consequence $d=0.83$. We could run a simulation to calculate the standard deviation and with it calculate the $u$ and $d$.

\section{Game Theory}

Real Options is relatively new and Game Theory has been thought for a long time in business school to simulate competitor's dynamics. Game theory is used to frame the option and the assumptions to analyze the business plan. ROA incorporated flexibility (to delay or to accelerate, to expand or to contract, to build or not to build) into the calculations, but it cannot examine the impact of the competition and preemption to invest that Game Theory does. In an efficient market, prices adjust rapidly and reflect all the information available. Real markets are not always perfectly competitive and investors can earn returns that exceed the cost of capital Practitioners called the portion that exceeds the cost of capital, economic rents.

An early investment only can produce temporary economic rents, because when investors find that somebody is getting them, as soon they have the information, they will invest too to get part of the economic rents, causing erosion on the economic rents of the first investor. Economic rents can have different sources, for example new product or new technology. When a patent protects the new product or the new technology, the owner of it creates a temporary barrier for other firms to entry as competitors. The barrier is temporary because patents have expiration or companies can develop similar improved products or similar technologies. Consequently, under perfect competition, economic rents are expected to decline; monopoly exists temporarily, and during that time rents are constant. In the absence of competition and other costs of waiting, the owner of a project could delay initiating a project. When a second competitor or second firm arrives, a duopolio is born and of course, economic rents are divided between the competitors. In addition, when more competitors arrive, competitive advantages no longer exist; economic rents disappear and each company gets only the cost of capital. Companies can preempt anticipated competitive arrivals, making a preemptive entry to the market to get economic rents before competitor(s) eroding its economic rents. Competitiveness cannot be analyzed under the previous valuation methods.

The following Table No. 5 contains the different types of games:

"Proceedings of the 2004 American Society for Engineering

Education Annual Conference \& Exposition

Copyright (C) 2004, American Society for Engineering Education”" 
Static Games: Each player makes decisions or selects a strategy simultaneously without knowledge of the strategies chosen by the other players. (It is called Static Bayesian and it is solved using the concept of a Nash equilibrium)
With Complete or Perfect Information: Players have perfect information if they know exactly what has happened every time a decisions needs to be made. Payoffs are common knowledge and each player has their own strategies. The result is an insufficient situation described by the "prisoners dilemma." Its situation is known as "Nash equilibrium." With Incomplete Information: Players act simultaneously and each player follows his or her own beliefs about the other player's payoffs when defining his or her actions
Dynamic Games or repeated games: Each player has assumptions and beliefs regarding the pay offs and potential future actions of the other player maybe based on previous moves
With Complete Information: One of the players acts first and the second observes the movement and then acts. It is a sequential game where one player moves at a time, each player knows every action from previous movements.

With Incomplete Information: If a player does not know exactly what actions other players took, he or she has the knowledge of their own pay offs but not the other player. Its situation is known as "Bayesian equilibrium.'

\section{Table No. 5 Static and Dynamic Games}

Smit and Ankum established the first connections between the Real Options concepts and Game Theory ${ }^{8}, 9$. They found that under a perfect market conditions some projects can be seen as a chain of subsequent investment decisions. Smit and Ankum discussed several possibilities: 1.- A monopoly when the economic rents remain constant due to a barrier entry. 2.- A competitive reaction where economic rents decrease over time due to a competitive entry and 3.- Duopoly (symmetric and asymmetric).

Smit and Trigeorgis ${ }^{10}$ studied strategic investments under competitive conditions, using a decision tree. Lambrecht and Perraudin ${ }^{11},{ }^{12}$ were the first to introduce incomplete information in their option games and found that in a highly competitive environment, companies tend to invest early to preempt entry for other competitors. Additionally, they found that preemptive entry could destroy the value of the option to wait.

"Proceedings of the 2004 American Society for Engineering

Education Annual Conference \& Exposition

Copyright (C) 2004, American Society for Engineering Education” 
Grow options under imperfect competition was studied by Kulatilaka and Perotti ${ }^{13}$. They found that a firm might loose the growth option by deferring the investment decisions to solve uncertainty. Additionally they found that aggressive investment reduces the value of the option.

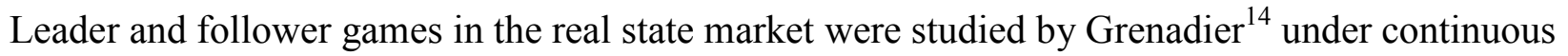
time. As kulatinaka and Perotti, he found, that a competitive pressure destroys the value of the option to wait. Grenadier models provides an explanation of a rational equilibrium foundation behind the cascades and booms of overbuilding followed by the insufficient supply of real state units: "Some times the markets sit idle for years and then blast of in a surge of construction." 15 His model demonstrates too that options might be exercises sequentially or simultaneously, depending on the conditions of the market. Additionally, he found that in a world of perfect information, option exercise could be conducted in isolation.

When a monopoly exists, the owner of the project decides when to build and how many units to build since there will always be people willing to buy the product. In this case, the economic returns of the project are assumed to be undiminished through time. But, on the other hand, when a builder is in a specific area and a competitor arrives, the consequences of moving from a monopoly to a duopoly need to be explored. There are different ways to explore these consequences:

The first way consists in studying the decrease in economic returns without looking at the number of competitors and their strategies. When a monopoly exists, a competitive reaction follows (other builders arrive because of the success of the first builder) and economic returns diminish throughout time until the project is no longer productive. The owner of the project then needs to do a better analysis of the erosion of economic returns.

In general, the builder can have two economic returns: The first one corresponds to the investment return of the shareholders or dividends that consists in an infinite constant annuity $(k I / k)$, where $I$ is the initial investment and $k$ is the rate of return. This return can be assumed to go forever ${ }^{1}$. The second return relates to the economic rents or extra piece or exceeding rent after the shareholders received the agreed return on capital investment. It can be assumed to go forever, too (mortgage companies make similar calculations when determining the value of an asset) and can be calculated with the formula of a Present Value for a growing (shrinking) perpetuity (Rent/(k-g), where $\mathrm{g}$ is the growing or shrinking rate). When shrinking, $\mathrm{g}$ is negative. The present value of the project will be calculated as follows:

$P V_{0}=\frac{k^{*} I}{k}+\frac{\operatorname{Re} n t}{(k-g)}$

Knowing the present value of the project, calculation can follow as was explained in the Real Option Approach section, framing the option into the NPV or DTA approach.

The second way to explore the consequences of having a competitor, consists in using the up and downs of the value of the project in the decision tree and in each node of the tree, finding the values of the possible four different investment tactics that can be in the game: a.- Companies $\mathrm{A}_{1}$

"Proceedings of the 2004 American Society for Engineering Education Annual Conference \& Exposition Copyright (C) 2004, American Society for Engineering Education” 
and $\mathrm{A}_{2}$ decide to invest simultaneously. b.- Companies $\mathrm{A}_{1}$ and $\mathrm{A}_{2}$ decide to wait. c.- Company $\mathrm{A}_{1}$ (the leader) decides to invest and company $\mathrm{A}_{2}$ (the follower) decides to wait. And d.Company $\mathrm{A}_{1}$ decides to wait and company $\mathrm{A}_{2}$ decides to invest.

Having four tactics in each node, the solution with the highest pay-offs or best responses are called Nash equilibrium (who gives the solution) for a game between two players. Figure No. 2 show the different games and solutions when two companies participate in the game.

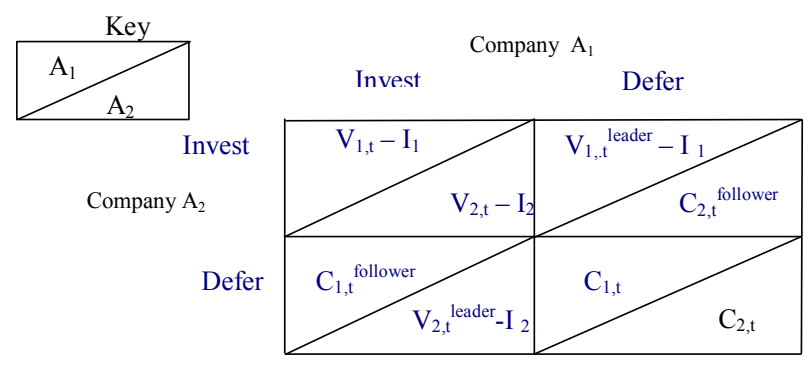

Fig No. 2 Investment Games

"Nash equilibrium is a collection of strategies, one for each player, that are mutual best replies in the sense that each agent's strategy is optimal given the strategies of the other agents" ${ }^{\prime 16}$. For the four strategies or tactics mentioned above, the solutions are as follows:

1. - If both companies $A_{1}$ and $A_{2}$ decide to invest simultaneously, the payoff for company $A_{1}$ will be $V_{1, t}-I_{1}$, and for company $A_{2}$ will be $V_{2, t}-I_{2}$, where $V_{1, t}$ is the value of the project of company 1 at the time $T$ and $I_{1}$ is the value of the investment of company 1. 2. - If both companies $A_{1}$ and $A_{2}$ decide not to invest (defer) simultaneously, the pay off for company $A_{1}$ will be the option to defer $C_{1, t}$, and for company $A_{2}$ will be the option to defer $C_{2, t}$. 3. - If company $A_{1}$ (the leader) decides to invest, the pay off for company $A_{1}$ will be $V_{1, t}-I_{1}$, while company $\mathrm{A}_{2}$ (the follower) has the option to invest or delay the investment. When company $\mathrm{A}_{2}$ decides to invest, the pay off will be $V_{2, t}-I_{2}$, and if it decides to differ, the pay off will be the deferment $C_{2, t}$. 4. -If company $A_{1}$ decides not to invest (defer), the pay off for company $A_{1}$ will be $C_{1, t}$, and company $A_{2}$ has the option to invest or delay the investment. When company $A_{2}$ decides to invest, the pay off will be $\mathrm{V}_{2, \mathrm{t}}-\mathrm{I}_{2}$, and if it decides to differ, the pay off will be the option to defer $\mathrm{C}_{2, t}$. We can consider here company $\mathrm{A}_{2}$ as the leader when it decides to invest and company $A_{1}$ as the follower with the option to defer its investment.

\section{Conclusions}

Net Present Value is an easy technique for determining if profit can be realized on a project since it simply takes the difference between revenues and expenses. However, this technique does not take into account factors like the flexibility to take decisions later instead of fixing all the outcomes at the present moment. NPV does not take into account the size of the project being analyzed and the cost-benefit associated with the value of the options to expand, contract, and the delay or the acceleration of the project.

"Proceedings of the 2004 American Society for Engineering Education Annual Conference \& Exposition Copyright (C) 2004, American Society for Engineering Education” 
Discount Cash Flow is familiar for many people too, and takes into account some managerial flexibility, but it has problems related with the assignment of the discount rate and the probabilities used to get the expected cash flows. Calculations could be very complicated when trying to incorporate many sources of uncertainties.

The Real Options Approach and the theory behind is more complex than the previous techniques and is practically unknown for common people an engineers. Some MBA programs are starting teaching students this technique applied to real projects. Because it is new, for beginning learners, is hard to trust and sometimes unclear when is time to make decisions, but it offer great flexibility since it takes uncertainty into account.

ROA allows to incorporate many sources of uncertainty without making the problem more complex, because uncertainties can be grouped in a single parameter: volatility. Options to delay, to expand or contract can be clearly analyzed in each node of the decision tree when it is added as a frame to analyze the managerial flexibility.

Probabilities are simpler and clearer in ROA than the DTA, because probabilities are the result of two payoffs. Additionally, because the discount rate is a risk free rate, the only difficulty is finding a good estimate for this rate, especially in underdeveloped countries where not many statistics exist related with the government bonds.

With a new project it is important to determine its price, since that is the underlying asset, but it is not easy to identify all sources of volatility and how they can affect its price. Game theory can be used in combination with ROA to develop ways to explain the interaction strategies between competitors. ROA and Game Theory are practically unknown for engineers, but given the opportunity to incorporate managerial flexibility and uncertainties is very promising in helping explain competitors' interactions.

\section{Bibliography}

\footnotetext{
${ }^{1}$ Ross S., R. Westerfield and J. Jaffee. 1996 “Corporate Finance”. Irwin, Chicago.

${ }^{2}$ De Neufville, R. Applied Systems Analysis: Engineering Planning and Technology Management, 1990. Mc GrawHill Publishing Company, US.

${ }^{3}$ Black F. and M. Sholes “The pricing of Options and Corporate Liabilities" Journal of Political Economy, 1973.Vol. 81, May-Jun pp. 637-54.

${ }^{4}$ Trigeorgis, L. "Real Options: Managerial Flexibility and Strategy in resource Allocation” 1998 MIT Press,.Cambridge, MA

${ }^{5}$ Samuelson, P. "Rational Theory of Warrant Price”. Industrial Management Review. 1967 6:13,1967

${ }^{6}$ Copeland, T. and V. Antikarov “Real Options: Apractitioner's Guide”, 2001.Texere, New York, NY.

"Proceedings of the 2004 American Society for Engineering Education Annual Conference \& Exposition Copyright (C) 2004, American Society for Engineering Education”
} 
${ }^{7}$ Nembhard, H., L. Shi and M. Aktan.”A Real Option Design for Quality Control Charts”. The Engineerig Economist 47:28, 2002.

${ }^{8}$ Smit, H. and L.A. Ankum, "A Real Options and Game-Theoretic Approach to Corporate Investment Strategy under Competition", Game Choices: The intersection of Real Options and Game Theory. Chapter 2 pp 21-27. 2000. Edited by Steven Grenadier, Risk Books London.

${ }^{9}$ Smit, H. and L.A. Ankum, “A Real Options and Game-Theoretic Approach to Corporate Investment Strategy under Competition”, Financial Management 1993. 22, pp 241-50.

${ }^{10}$ Smit, H. and L. Trigeorgis, "Flexibility and Commitment in Strategic Investment". Working paper, 1993. Tinbergen Institute, Erasmus University, Rotterdam.

${ }^{11}$ Lambrecht B. and W. Perraudin “ Real Options and Preemption,” Working paper 1996 Cambridge University, and Birkbeck College, London, UK.

${ }^{12}$ Lambrecht B. and W. Perraudin “Option Games” Working paper 1994 .Canbridge University, and CEPR, UK.

${ }^{13}$ Kulatilaka N. and E.C. Perotti "Strategic Growth Options" 1998. Management Science 44: 1021.

${ }^{14}$ Grenadier S.. "Information Revelation Through Option Exercise." Game Choices: The intersection of Real Options and Game Theory. Chapter 6. pp 125-159. 2001. Risk Books, London.

${ }^{15}$ Grenadier S. . "The strategic Exercise of Options: Development Cascades and Overbuilding in Real States Market", 1996. Journal of Finance 51, pp 1653-79

${ }^{16}$ Samuelson, L., Evolutionary Games and Equilibrium Selection. Cambridge, Massachusetts. 1997. The MIT Press.

\section{Author}

Martha Garcia-Saenz. Assistant Professor of Building Construction Management. Purdue University North Central Campus.mgarcia@pnc.edu 